\title{
PRECISION TEACHING AND FLUENCY: THE EFFECTS OF CHARTING AND GOAL-SETTING ON SKATERS'PER- FORMANCE
}

\author{
Trudy L. Pocock, T. Mary Foster, and James S. McEwan \\ The University of Waikato
}

\begin{abstract}
This research involved three successive studies where precision teaching methods were used to increase roller skaters performance rates of basic skating skills. The first study compared precision teaching methods both with and without the use of charting in a group design, and compared both within-subject and betweensubject differences for 12 skaters. Results showed that charting did not increase performance rates over that seen when charting was not used. The second study was a group design which compared two different types of goals, or performance aims, on skaters' performance. No difference was found between the two groups of 5 skaters when one group used a fixed, difficult goal and a second used a flexible, easier goal. In the final study, a single-subject design was used and 8 skaters completed a control condition where no goals were set before a goal was introduced for 4 skaters. It was found that an immediate increase in performance rates occurred following the introduction of the goal. Overall these three studies showed that skaters improved their performance rates over sessions, even in the absence of charting and/or goals, demonstrating that precision teaching can be applied to the sport of roller skating. Keywords: precision teaching, fluency, sports performance
\end{abstract}

Precision teaching is based on the learning principles of B.F. Skinner (Binder \& Watkins, 1990; Lindsley, 1990; Lindsley, 1971) and it focuses on developing fluent behaviour, i.e., fast and accurate performance of the behaviour (Binder \& Watkins, 1990). Precision teaching has mainly been used in education (Chiesa \& Robertson, 2000; Kessissoglou \& Farrell, 1995; Lindsley, 1990; Lindsley, 1992a, 1992b) but it does seem that it could be applied to motor skills such as those used in rollerskating. A major aspect of the procedure is repetition of a skill, or behaviour, within timed periods. The rate at which a skill is performed in those periods is

\footnotetext{
Address all correspondence to:

James McEwan

Department of Psychology

University of Waikato

Private Bag 3105

Hamilton, New Zealand

Email:jmcewan@waikato.ac.nz
}

used as a measure of performance and is recorded on a chart. Previous research has shown that performance becomes more fluent than it would have otherwise when precision teaching is used (Johnson, 1997; Spence \& Hively, 1993). However, there is no research into which components of the procedure make this method effective and so it is not clear whether all components contribute to the increased fluency.

One component of precision teaching is the use of charts. Lindsley (1971) developed these charts for teachers to use and termed them celeration charts. They allow data to be presented in a familiar, standardised, way to everyone who uses precision teaching methods. Lindsley argued that such standard charts allow different practitioners to compare progress of one individual with others. These charts plot both correct and error frequencies across days and usually include a goal or performance aim which 
is an indication of the rate of performance that the person is aiming to achieve. They have a logarithmic y-axis so that learning curves are viewed as straight-line trends (Binder \& Watkins, 1990).

Lindsley (1971) suggests these charts may serve several different functions. For example, upon viewing celeration charts, practitioners and teachers often change their teaching programme in an attempt to accelerate target behaviour. In these cases, any changes in the rate of performance, as a result of a change in teaching programme, are attributable to that new teaching programme, and not the use of the celeration chart. However, Lindsley (1990) reports that many teachers who have used charting state that charting alone accelerates academic performance. Binder and Watkins (1990) report that over time "learning pictures" are created on each celeration chart as more data are added, giving students and teachers a clear picture of improvements and plateaus. Johnson and Layng (1992) suggest this makes it easy for students and/or teachers to make quick, daily decisions about progress. Students also become their own fluency coaches because they are improving their performance through daily practice, self-monitoring via the chart, decision making based on the chart, and selfcorrection. It is also possible that charts are used by both students and teachers as a basis for discussion and making decisions on future learning strategies. Yawkey and O'Meara (1974) found that when a teacher used celeration charts with children, the children's mathematical performances were better than those of other students not using celeration charts. In their study all children were tested on single and double digit addition problems for a minute each day. In both of two conditions, children graphed the number correct onto vertical bar graphs. In one condition the experimenter then also graphed their performances on celeration charts. During this same condition the teacher analysed the celeration chart, discussed learning opportunities with the child and suggested additional work that the child could do to improve their responding. The celeration charting combined with the teacher feedback increased performance. It is not clear how much the viewing of progress on a celeration chart alone contributed to the increased performance.

It may be that charts alone can alter behaviour through the visual feedback that they provide (Alper \& White, 1971). Once data has been plotted onto a graph, the plot may indicate to the learner what progress is being made and this may function to aid behaviour change. Johnson (1971) reports a student being "motivated" by the charting process because it "showed her that she was learning"(p.110). Based on his claims, Ayers, Potter, and McDearmon (1975) used charting with four adult aphasics and reported that the charting "motivated" the participants in the study which in turn produced changes in their specified language behaviours. Unfortunately "motivation" is an abstract term that was not quantified in this study and so it is not possible to conclude how much charting changed the behaviour of the participants.

In another study Brandstetter and Merz (1978) report that charting resulted in increased reading rates for $4^{\text {th }}$ graders. They argue that their results confirm what Lindsley (1990) and earlier researchers have said about charting being an essential part of precision teaching. Their data suggest however that the semi-logarithmic celeration charts were not as effective as non-logarithmic charts. They actually found that there was no significant effect of celeration charts compared to no charting but did find non-logarithmic charts had an effect. Unfortunately, the two sample groups used differed greatly from each other in that each group of students was 
at a different stage of learning and so this may have impacted on the results found in this study. Thus the data cannot be taken to suggest that semilogarithmic charts are superior to nonlogarithmic plots.

In summary then, research in the area of charting appears to be limited. While many authors suggest that charting is an essential part of precision teaching (Lindsley, 1971; Raybould \& Solity, 1982; West, Young, \& Spooner, 1990; White, 1986), there is not a large amount of research to validate this. Some of these authors report that their research demonstrates the importance of charting, however, none looks into why charting may be effective.

One possibility is that visual feedback, which charting provides, may contribute to the effectiveness of precision teaching. The first aim of this study was to explore this further by comparing the performances of beginner skaters learning two skills, where a full precision teaching procedure was used with one skill and precision teaching without charting was used with the other. A group design was needed to compare the same skill over different skaters. As all skaters needed the same amount of exposure to training, a set number of sessions were used. In this case, ten were possible. As neither skill had been used with precision teaching methods previously it was not possible to be certain that one skill could not be learnt more easily using precision teaching methods than the other. For this reason, half of the participants used charting with one skill while the other participants used charting with the alternate skill. This allowed a comparison to be made between skills for both charting and noncharting conditions.

As a group of skaters who did not participate in the study was available, a second aim was to see if the effect of precision teaching, when applied to a sporting skill such as roller skating, was greater than standard training. The progress on standard skating assessments of those skaters in the study was compared to the remaining skaters attending the beginner training class. It was expected that if precision teaching could be applied to roller skating and was effective in increasing overall skating ability, progress on standard skating assessments would be greater for those participating in the precision teaching.

\section{METHOD}

\section{Participants}

Twelve children (P1-P12) from the local beginner roller-skating class participated. The 6 participants in Group 1 (P1-P6) were aged between 6 and 13 years at the start of the study with an average age of 9.0 years. There were 5 girls and 1 boy. The participants in Group 2 (P7-P12) were all girls aged between 6 and 9 years with an average age of 7.8 years. All participants completed the study.

\section{Apparatus}

A cassette tape containing the words "three, two, one, GO" indicated the beginning of each 1-min interval followed by three short tones every 15 seconds until the word "O.K." indicated the end of a timed minute. This sequence was repeated on the tape a number of times and was used to time the 1-min periods of skating. Some of the skating sessions were recorded on video using a Sony Handycam Vision camcorder.

\section{Procedure}

Two roller skating skills, forward crossovers and back scissors, were the targeted skills. Definitions of each skill were established and, because the purpose of using precision teaching was to increase fluency, performance aims of 50 correct repetitions per minute were set for both skills. The performance aims were based on observations of an experienced, fluent skater at the rink. 
Forward crossovers allow skaters to skate forwards around corners. This skill includes the crossing action of one skate across the front of the other. To perform this accurately, while moving forward, the skater must lift the first skate off the skating surface and place it back on the rink surface either directly in front of the second skate or to the outside of the second skate so that the skaters little toes are now next to each other. Then they lift the second skate from the skating surface so that they are rolling on the first skate only. In this study if the skater did not cross the first skate far enough over the second skate or fell at any point then that repetition of the skill was counted as an "attempt" rather than a "correct".

To execute a backward scissor correctly, the skater must move both skates simultaneously firstly away from each other and then back towards each other. In this study, to be correct, both skates had to be rolling throughout the manoeuvre. If one or both skates became stationary, or the skater fell or overbalanced resulting in the wheels of at least one skate leaving the rink surface, then that repetition of the skill was recorded as an 'attempt'.

Initially all skaters attending local beginner classes were given an information sheet and consent form to hand on to their parents. The information sheet outlined the main researcher's background in skating and that she was a qualified skating coach, and a general overview of the study. Parents were invited to sign the consent form if they wished their child(ren) to take part in the research. Consent forms were obtained for 12 participants. These skaters were then randomly assigned to either Group 1 or Group 2. Participants in the study were required to commit to attending two 15-20 minutes sessions at the skating rink for the duration of the study.

At the first meeting at the rink the researcher explained to each child what was going to happen at the sessions and confirmed that the child was prepared to participate. Each skater was told that over the next 5 or 6 weeks they would be learning two important basic skating skills, forward crossovers and back scissors. At the end of this time they should be able to do these two skills faster and easier. To see how much faster they were getting, the number of forward crosses or back scissors they were doing in one minute would be counted. Skaters were told they would have three attempts at doing this for both skills each time they came to the rink and that they would be aiming to do 50 repetitions in one minute. However, for this first meeting they were told they would simply be taught the two skills and then have a chance to practice doing each of the skills for $1 \mathrm{~min}$ while their performance was recorded on video.

Skaters were then shown a sample celeration chart with data points already plotted and the chart was explained to them. Each child was asked questions relating to the chart to check their understanding of it. The experimenter then taught them the skill that they would be charting in the study. Following a 1-min practice of that skill each child plotted the results of that timing onto a clean celeration chart.

Each skater was recorded on video during a 1-min practice. For one participant, P4, this was not possible due to technical problems. P10's performance was not recorded at the request of her parents.

The second meeting at the rink was treated as the first experimental session. There were ten experimental sessions scheduled across 5 weeks. If a skater did not attend a scheduled session then this session was counted as a missed session. Missed sessions were included towards the total number of sessions to ensure that all skaters started and stopped the experiment during the same time period. 
At each experimental session the skater was given the opportunity to nominate which skill they performed first, but were encouraged to change which one they chose each time. The researcher reminded each skater at all sessions what performance aim they were trying to reach. During the study it became clear that some children were able to perform the skills much faster than the experienced skater on which the performance aim had been set. Thus skaters who surpassed the performance aim of 50 were given a new aim of 60 . When it became clear further increases were possible new aims were given in multiples of 10 i.e. $70,80,90$, and 100 . Before each of the three timings in a session the researcher had the skater practice the current skill about to be observed until they had done it correctly at least once and gave feedback to them on each try. The timing was then started and the researcher counted corrects and errors.

Upon completion, the skater was told how many correct and incorrect repetitions they had completed. This was done for both skills. While Group 1 participants plotted their results for forward crosses on a celeration chart, Group 2 participants plotted the results of their back scissors on a celeration chart.

At the completion of Session 10 the skaters were asked to do an extra 1-min timing for each skill and this was recorded on video. P10 was again not recorded on video at the request of her parent.

As part of the normal programme for beginner classes, after each 10 week block skaters are assessed on a range of basic skating elements to determine what level they are performing at. The ten items tested at each level include elements of forward skating, backward skating, turns, spins, one foot balances and jumps. A club coach responsible for this assessment tested all beginner skaters the week following the final session of this study. Skaters in this study were then compared with the 7 other skaters who attended the beginner sessions to determine whether training in two basic skating skills affected their ability to perform other basic skating skills.

To establish the level of interobserver reliability, the experimenter and two other observers watched the video taken of each skater and recorded the number of correct and incorrect executions. The University of Waikato Psychology Research and Ethics Committee approved all studies.

\section{RESULTS}

Initially data from both Groups 1 and 2 were plotted on celeration charts. However, to estimate the rate of change over timings the data were re-plotted using a linear scale and are shown in Figure 1 where P1 to P6 correspond to the participants in Group 1 and P7 to P12 to the participants in Group 2. The timings completed are represented on the $\mathrm{x}$-axis while the number completed per-minute are represented on the y-axis. Solid lines represent forward crosses and broken lines represent back scissors. Circle markers represent correct repetitions of each skill while crosses represent incorrect repetitions.

Skaters in Group 1 (P1-P6) counted and charted forward crosses and just counted back scissors, and were initially aiming for 50 correct repetitions per minute for both of these skills. All skaters except $\mathrm{P} 4$ reached this aim for forward crosses with two skaters attaining 70 correct repetitions per minute. These same two skaters were the only two to attain 50 correct repetitions for back scissors reaching scores of around 90100 correct repetitions per minute. The other four skaters were not able to reach the goal for back scissors. P6 changed from rollerblades to roller skates at Timing 15 which resulted in a drop in the number of correct repetitions for both 

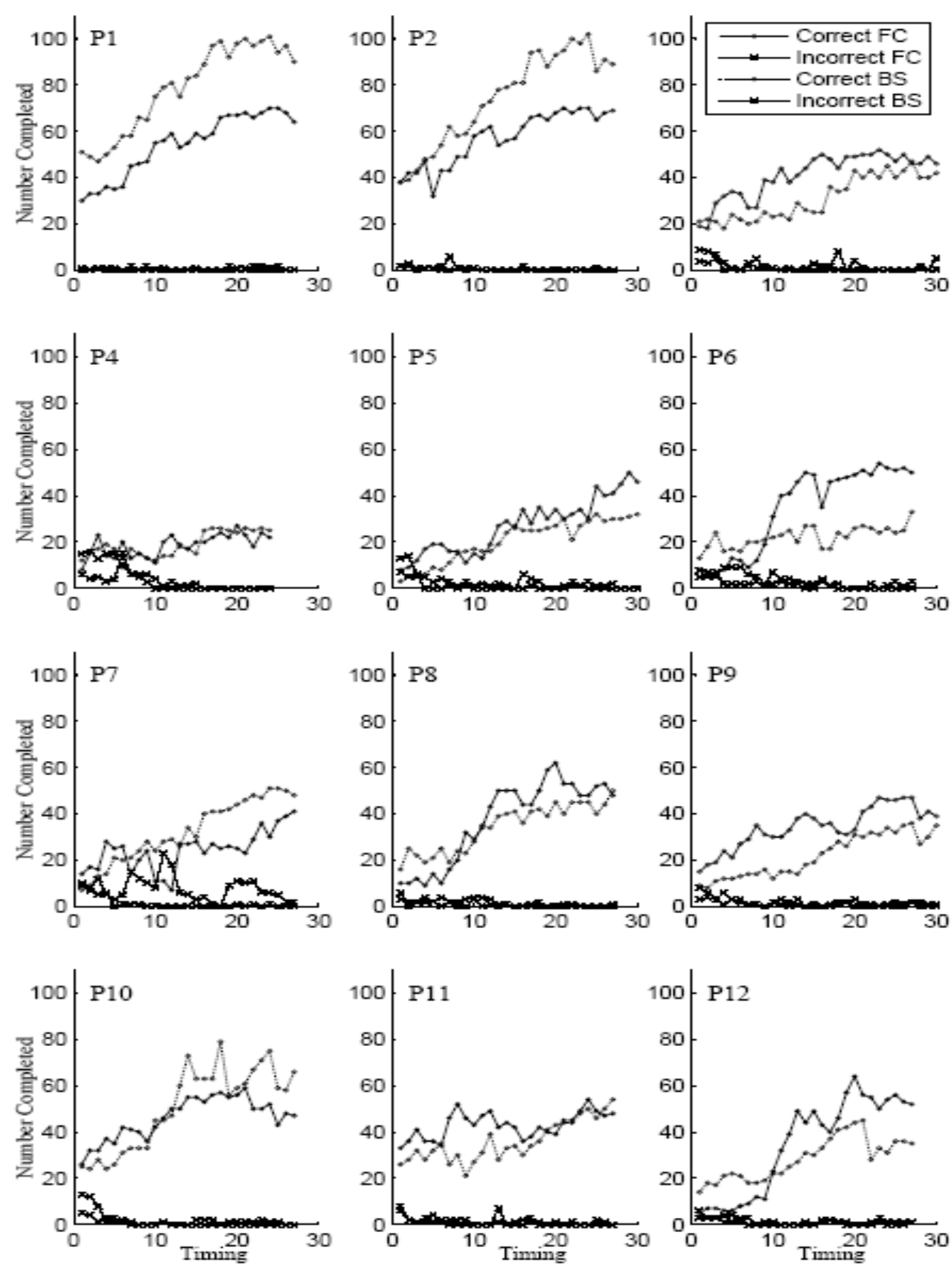

Figure 1. Number of correctly and incorrectly completed forward crosses (FC) and back scissors (BS) performed in one minute for six participants in Group 1 (P1 to P6) and six participants in Group 2 (P7-P12) across ten sessions. Each session included three 1-min timings. Participants in Group 1 were charting their forward crosses while participants in Group 2 charted their back scissors.

skills.

Skaters in Group 2 (P7-P12) counted forward crosses and charted back scis- sors, and were aiming for 50 correct repetitions per minute for both of these skills. Three of the 6 skaters reached the 
goal of 50 correct repetitions per minute for both skills. One skater failed to meet this aim for either skill. The remaining two skaters in this group reached the aim for one skill only.

Lines were fitted to these data by the method of least squares regression. Table 1 shows the slopes and intercepts of the lines for individual skaters for both skills. Comparison of the slopes for the two skills shows that for Group 1 only two skaters improved faster on the charted skill (forward crosses). In Group 2 , four skaters improved faster on the charted skill (back scissors). Overall the data show that four skaters in each group improved faster on back scissors than on forward crosses regardless of whether charting was used or not. Generally, however, the obtained slopes for Group 1 and 2 were similar for both skills, with differences greater than 1 being seen in only 4 individuals' data. A repeated measures ANOVA confirmed that, with alpha set at .05 , there was no significant difference in slope between the two skills, $\mathrm{F}(1,10)=.013, \mathrm{p}=.911$ (partial $\eta^{2}=.001$ ), or between groups, $\mathrm{F}(1,10)=.010, \mathrm{p}=.921\left(\right.$ partial $\eta^{2}$ $=.001)$.

The first and last timings were also compared using a split plot ANOVA (mixed design analysis of variance) comparing groups, skills and timings. With alpha set at .05 , the interaction of these three variables was not statistically significant $\mathrm{F}(1,10)=.356$ (partial $\eta^{2}$ $=.034$, observed power $=.084)$. There was also no significant difference between skills, $\mathrm{F}(1,10)=.559$ (partial $\eta^{2}$ $=.053$, observed power $=.104$ ), or between groups, $\mathrm{F}(1,10)=.235$ (partial $\eta^{2}$ $=.023$, observed power $=.072$ ). However, a significant difference was found between first and last timings, $F(1,10)=$ 166.93 (partial $\eta^{2}=.943$ ).

Interobserver reliability was determined by finding the mean percentage agreement between observers. The fol- lowing formula was used to find each percentage agreement:

$\underline{\text { Smallest number observed }} \times 100$

Largest number observed

Results showed that interobserver reliability was high, ranging from $89.13 \%$ to $100 \%$ with a mean percentage agreement of $97.62 \%$ (standard deviation = 3.10 ). Percentage agreement is not presented for incorrect observations as lower numbers of errors occurred (averaging 3.698 across observers) and therefore any small differences gave large variances in the interobserver measures.

The club coach assessed all skaters in the beginner class. Beginner skaters typically progress 1 level per term but this assessment determined that 9 of the 12 skaters in the study had progressed two levels during the ten weeks of the beginners' class. The remaining 3 skaters in the study had progressed one level, as had the 7 beginner class skaters who had not participated in the study.

\section{DISCUSSION}

This study examined the effects of charting skills using celeration charts. Overall, charting did not result in greater improvement for one skill over the second uncharted skill but fluency training resulted in improvements across all skaters and both skills. Furthermore the progress on standard skating assessments was greater for skaters participating in the study than for other skaters attending the beginners' class.

This study purposely separated out only one component of precision teaching, charting, to determine how effective this component was. That charting alone had little effect is inconsistent with the generally reported view that charting contributes to the effects of precision teaching (Lindsley, 1990). However, the results presented here are similar to previous research done by Brandstetter and Merz (1978) who examined the 
Table 1. Slopes and intercepts for each participant for forward crosses (FC) and back scissors (BS) and the differences between skill intercepts and slopes for each participant.

\begin{tabular}{c|r|r|r|r|r|r}
$\begin{array}{c}\text { Participant } \\
\text { (group) }\end{array}$ & \multicolumn{1}{|c}{$\begin{array}{c}\text { FC } \\
\text { Intercept }\end{array}$} & \multicolumn{1}{c}{$\begin{array}{c}\text { FC } \\
\text { slope }\end{array}$} & \multicolumn{1}{c}{$\begin{array}{c}\text { BS } \\
\text { Intercept }\end{array}$} & \multicolumn{1}{c}{$\begin{array}{c}\text { BS } \\
\text { slope }\end{array}$} & \multicolumn{1}{r}{$\begin{array}{r}\text { FC-BS } \\
\text { Intercept }\end{array}$} & \multicolumn{1}{c}{$\begin{array}{c}\text { FC-BS } \\
\text { slope }\end{array}$} \\
\hline P1 (1) & 32.251 & 1.580 & 47.735 & 2.217 & -15.484 & -0.637 \\
P2 (1) & 38.405 & 1.331 & 40.977 & 2.385 & -2.573 & -1.054 \\
P3 (1) & 26.885 & 0.926 & 15.938 & 0.985 & 10.947 & -0.059 \\
P4 (1) & 12.732 & 0.465 & 11.286 & 0.610 & 1.446 & -0.146 \\
P5 (1) & 7.108 & 1.281 & 5.170 & 0.993 & 1.938 & 0.288 \\
P6 (1) & 5.390 & 2.089 & 16.598 & 0.402 & -11.208 & 1.687 \\
P7 (2) & 13.792 & 0.750 & 8.815 & 1.691 & 4.977 & -0.940 \\
P8 (2) & 9.353 & 1.985 & 17.630 & 1.183 & -8.276 & 0.803 \\
P9 (2) & 20.740 & 0.877 & 6.517 & 0.992 & 14.223 & -0.115 \\
P10 (2) & 34.547 & 0.826 & 23.476 & 1.940 & 11.071 & -1.114 \\
P11 (2) & 37.558 & 0.383 & 22.635 & 0.949 & 14.923 & -0.566 \\
P12 (2) & 0.803 & 2.411 & 15.097 & 0.948 & -14.294 & 1.463
\end{tabular}

effects of charts on reading rates for $4^{\text {th }}$ graders.

Differences found in their study were small, although non-logarithmic charts showed a bigger effect. This contrasts with Yawkey and O'Meara (1974) who found, when the teacher used celeration charts with children, that mathematical performances were better than when they were not using celeration charts. However, as already pointed out, these results were confounded as teachers used the celeration charts to make suggestions on specific follow up activities that the children could engage in to decrease errors. The present findings support the idea that the activities contributed to children in the charting phase outperforming those that were not rather than this being an effect of charting alone.

The main procedural difference resulting from the use of charts is the provision of visual feedback. This may, in and of itself, change the behaviour of students. Dvorak, Merrick, Dealey and Ford (Joyce \& Moxley, 1988) state that charts provide students with feedback that allows them to compete with their own record and see their results. How- ever, given the similar results found for both charted and non-charted skills, charts did not appear to provide an advantage.

As both skills were being counted, it was easy for skaters to compare the rates of the two skills. Skaters may have used this information to keep the rate of the uncharted skill either above or close to the rate of the charted skill. Therefore charting may have helped to accelerate rate of performance for both skills. It was not clear if this was the case. Even if it was, it does imply that the visual feedback was not required to help improve performance.

Using charts resulted in another procedural difference between conditions in this study. This was the degree of talk between experimenter and student and the potential for social feedback that may come from viewing charts with other people. For example, because a performance aim had been set and was drawn onto each participant's celeration chart, it was common for the experimenter and participant to discuss how close the current rate was to the performance aim. This resulted in both more discussion between the skater and researcher, 
and more social reinforcement relating to progress on that skill. However, this did not result in greater fluency gains than when the performance aim was discussed in the absence of a celeration chart.

While it is argued here that the data suggest charting alone had no effect, there is another aspect of the study worth discussing. White and Haring (1980) suggest that while feedback is important for precision teaching, feedback alone will not result in continued interest in the set task. Performance aims, or goals, are an integral part of precision teaching and charting (Koorland, Keel, \& Ueberhorst, 1990). The provision of these performance aims may have accelerated performance over and above that which would have been seen if only feedback had been given. Results show that once many of the skaters had reached, or come close to, the initial performance aim of 50 for one skill, their progress levelled off for both skills even though a new performance aim was set. This was true for 7 of the skaters who reached the performance aim for forward crosses and 3 of the skaters who reached the performance aim for back scissors. It is possible that skaters either found it difficult to go beyond this performance aim, or further performance aims had no effect. However, three skaters progressed well beyond the performance aim of 50 for both skills with a leveling off finally appearing at around 70 for forward crosses and 100 for back scissors. This suggests it was not impossible to achieve a higher performance rate. Perhaps if a higher performance aim had been set to start with, the plateaus seen in other skaters' results may not have occurred.

Performance aims are essentially a goal. Latham and Baldes (1975) suggest that goals lead to an increase in performance because they make it clear to individuals what is expected. It is also clearer to the individual what progress has been made as well as what progress could be expected in the future given his or her previous results. As pointed out previously, precision teaching often deliberately focuses on providing this feedback by drawing performance aims, or goals, onto the charts. There has been no research into the effectiveness of the use of such performance aims or goals in precision teaching. However, there is a lot written on the subject of goalsetting in the areas of cognitive and sport psychology (Anderson, Crowell, Doman, \& Howard, 1988; Boyce, Johnston, Wayda, Bunker, \& Eliot, 2001; Brett \& VandeWalle, 1999; Fairall \& Rodgers, 1997; Gilliland \& Landis, 1992; Hatzigeorgiadis \& Biddle, 1999; Kanfer \& Ackerman, 1994; Kozlowski et al., 2001; Latham \& Kinne, 1974; Rizzo et al., 2003; Thill \& Cury, 2000; Wanlin, Hrycaiko, Martin, \& Mahon, 1997; Weinberg, 2002) and much of it falls under the heading of goal-setting theory.

\section{Goal-setting theory}

Goal-setting theory attempts to explain the way in which performance on work tasks is regulated by conscious goals (Locke, 1993). Locke (1991) reports that "the efficacy of goal-setting in improving task performance is one of the best established findings in management and psychology" (p.311). Locke (1991) says that goal-setting theory has also been used to explain performance within academic and sporting fields. Locke and Latham (1985) claim that goal-setting may be an even more effective intervention in sports than in typical organizational settings. Others disagree. Boyce, Wayda, Johnston, Bunker and Eliot (2001) report that while approximately $90 \%$ of the goal-setting research in the Industrial/Organizational sciences has demonstrated that goals are effective, only $70 \%$ of the research studies within the area of Sport and Physical Activity show the same. 
Latham and Locke (1979) outline the critical components of goal-setting. They suggest goals should be specific and whenever possible there should be a time limit for accomplishment of the goal. They suggest that, when goals are specific, individuals may expend greater effort, and even devise better or more creative tactics, to attain the goal than they would have ordinarily. Precision teaching does set specific, time-based goals. Typically this is done by drawing the performance aim onto the celeration chart at the date by which it should be reached (Johnson \& Layng, 1996; Joyce, 1988; Koorland et al., 1990; Meacham \& Wiesen, 1969; Polson, 2003; White \& Haring, 1980). It may be these goals contribute towards the effectiveness of precision teaching.

Latham and Locke (1979) state that the goal should be challenging, yet attainable. Locke and Latham (1990) report that there is a linear relationship between degree of goal difficulty and performance which they refer to as the "goal difficulty function" (p. 27). They say that, assuming the goals set are accepted by the individuals, "hard goals lead to greater effort and persistence than easy goals" (Locke \& Latham, 1990). Latham and Seijts (1999) suggest that a difficult goal is one that only $10 \%$ of the participants can attain under normal conditions where goal-setting is not specifically used. As a result, many participants are in effect aiming for something that is beyond their reach and so are unrestricted by a maximum (Locke \& Latham, 1990). Locke and Latham (1990) report that a higher level of performance is achieved when goals that are specific and difficult are used rather than vague, non-quantitative goals such as "do your best". They reported mean effect sizes ranging from .42 to .80 for studies which compared hard, specific goals to "do your best" goals (Locke \& Latham, 1990; 2002). Precision teaching performance aims are based on the per- formance of a competent person, and so are normally achievable but should be challenging for the learner (Koorland et al., 1990). Therefore it is argued that precision teaching performance aims fall within the definition of a difficult goal.

It was found in Study 1 that charting alone did not accelerate the performance of skaters. However, improvements were seen over the course of the study. These improvements were greater than those seen with other skaters who had not taken part in the study. It is not clear what aspects of the training gave rise to the performance increases. A lot of research on goal-setting supports its effectiveness in improving performance over and above that which occurs when no goals are used. Thus it seems viable that the performance aims used in Study 1 may, at least in part, have been responsible for the improvement in performance.

Most of the goal-setting literature states that specific, hard goals are most effective. As pointed out, precision teaching uses performance aims which generally meet these criteria. It was argued earlier that, in the previous study, the goals set may not have been hard enough. This argument was post hoc and based on the fact that a few skaters went far beyond the initial performance aims, while others failed to improve once they reached it. It was reasoned that this occurred because the initial performance aim was too easy. Therefore the next study aimed at exploring the effect of the difficulty of a performance aim on the performance rates of a skating skill. To avoid the potential confounds from one condition to the other, as may have occurred in the previous study, two different groups and one skill were used. Otherwise all other procedures were the same as in the condition in the first study in which charting was not used. It was necessary to select a new skill to train and it was decided to use back crossfronts as the skill, which was a skill 
that no skaters in the beginners' class had previously been taught. This allowed skaters from Study 1 to participate. To test the effect of goal difficulty on performance, two different goals were set. One group was given a hard performance aim that met the criteria of being challenging, yet attainable. It was expected that only a few skaters would achieve this across the time-frame of the study. The goal was set close to the maximum of what was achieved in the first study on forward crosses as the movements involved in both forward crosses and back crossfronts are similar in size. The easy goal was based on what each skater was already achieving currently and so it was expected that skaters could easily reach this goal most sessions. It was expected that those skaters who were given a hard goal, or performance aim, would outperform those who were simply trying to equal their previous performance.

\section{STUDY 2 METHOD}

\section{Participants}

Ten children (P1-P10) from the local beginner roller-skating class participated. Eight of these skaters had participated in Study 1. The 5 participants in Group 1 (P1-P5) were girls aged between 7 and 9 years at the start of the study with an average age of 7.8 years. The participants in Group 2 (P6-P10) were aged between 8 and 12 years with an average age of 7.8 years. There were 4 girls and 1 boy. All participants completed the study.

\section{Apparatus}

A stopwatch was used to time each 1min interval. Some of the skating sessions were recorded on video using a Sony Handycam Vision camcorder.

\section{Procedure}

Back crossfronts were the skill targeted for this study. They allow skaters to skate backwards around corners and include the crossing action of one skate across the front of the other. Skaters perform this accurately, while moving backward, by lifting the first skate off the skating surface and placing it back on the rink surface either directly in front of the second skate or to the outside of the second skate so that the skaters' little toes are now next to each other. Then the second skate is lifted from the skating surface so that they are now rolling on the first skate only. If the skater does not cross the first skate far enough over the second skate or falls at any point then that repetition of the skill is counted as an "attempt" rather than a "correct".

Initially all skaters attending local beginner classes who could skate backwards, i.e., perform back scissors correctly, were given an information sheet and consent form to hand on to their parents. The information sheet was similar to that used in Study 1 as was the procedure for gaining consent. Consent forms were obtained for 10 participants and these skaters were then randomly assigned to either Group 1 or Group 2. Participants in the study were required to commit to attending two 10 minute sessions at the skating rink for the duration of the study.

At the first session each skater was told that over the next several weeks they would be learning to skate backwards around corners and that at the end of this time they should be able to do this skill faster and easier. All skaters were then told that in order to see how much faster they were getting, we would count how many back crossfronts they were doing in one minute and that they would have three attempts at doing this in each session. Before each of the three timings the researcher would observe the skater performing the skill and if necessary provide feedback to them until they had done it correctly. All sessions took place over the same 5 week 
time period. The tenth session coincided with the start of school holidays, during which all skating activities at the rink ceased and so the study stopped at this point. All skaters completed at least 9 sessions and 4 skaters completed 10 sessions.

From Session 2 onwards, at the start of the session, Group 1 skaters were told the highest number of correct back crossfronts they had performed in a minute in the previous session. They were told to aim at completing the same or more than this in the current session. Group 2 skaters were given the harder goal of 70 correct back crossfronts per minute at the beginning of each session. Following the completion of the last session, each skater was recorded on video during a 1-min practice. To establish the level of interobserver reliability, the experimenter and two other observers watched the video taken of each skater and recorded the number of correct and incorrect executions.

\section{RESULTS}

Figure 2 shows the number of correct and incorrect back crossfronts completed for both Group 1 and 2. The xaxis represents consecutive 1-min timings with three 1-min timings in each session. The y-axis represents number completed per minute. Correct back crossfronts are represented in a solid black line with round markers and incorrect back crossfronts are represented by a solid line with triangle markers. A broken line from timing 4 onwards shows the goal set for each session. The goal was determined by the highest score in the previous session for participants in Group 1. The goal was set at 70 repetitions per minute for Group 2.

From Session 2 on, all skaters in Group 1 were aiming to equal or better their best performance from the previous session, i.e., complete the same number of back crossfronts or more in one minute than they had in the last session.
For all skaters the goal increased from one session to the next in the majority of sessions. However, there were also times when the goal had to be lowered in the next session because the skater had not reached the goal at all for a session. One skater, P5, had their goal lowered for each of the last three consecutive sessions because their performance rate kept falling, making it necessary to set a lower goal each time.

From Session 2 onwards all skaters in Group 2 were aiming for 70 correct back crossfronts per minute. One skater managed to achieve this in his very last timing. The performance of the remaining skaters remained a clear distance below this goal.

Straight lines were fitted to the data presented in Figure 2 by the method of least squares. Table 2 shows the slopes and intercepts of the lines for individual skaters for both skills. Overall the slopes were very similar between Group 1 (M $=.844, \mathrm{SD}=.254)$ and Group $2(\mathrm{M}=$ $.907, \mathrm{SD}=.163)$. There was a numerical difference between the intercepts for Group $1(\mathrm{M}=12.263, \mathrm{SD}=6.494)$ and Group $2(\mathrm{M}=22.924, \mathrm{SD}=11.256)$. An independent samples t-test found that, with alpha set at .05 , there was no significant difference between slopes, $\mathrm{t}(8)$ $=.464$, or intercepts, $\mathrm{t}(8)=1.835$.

The first and last timings were also compared using a repeated measures ANOVA comparing groups and first timings with last timings. With alpha set at .05 , there was a significant difference from first to last timing, $\mathrm{F}(1,8)=$ 124.749 (partial $\eta^{2}=.940$ ), but no significant difference between groups, $\mathrm{F}(1$, $8)=.3 .583\left(\right.$ partial $\eta^{2}=.309$, observed power $=.385)$. The interaction of groups and timings was also not statistically significant $\mathrm{F}(1,8)=1.908\left(\right.$ partial $\eta^{2}=$ .193 , observed power $=.230$ ).

Interobserver reliability was determined for two observers, the experimenter and a local club coach, by find 

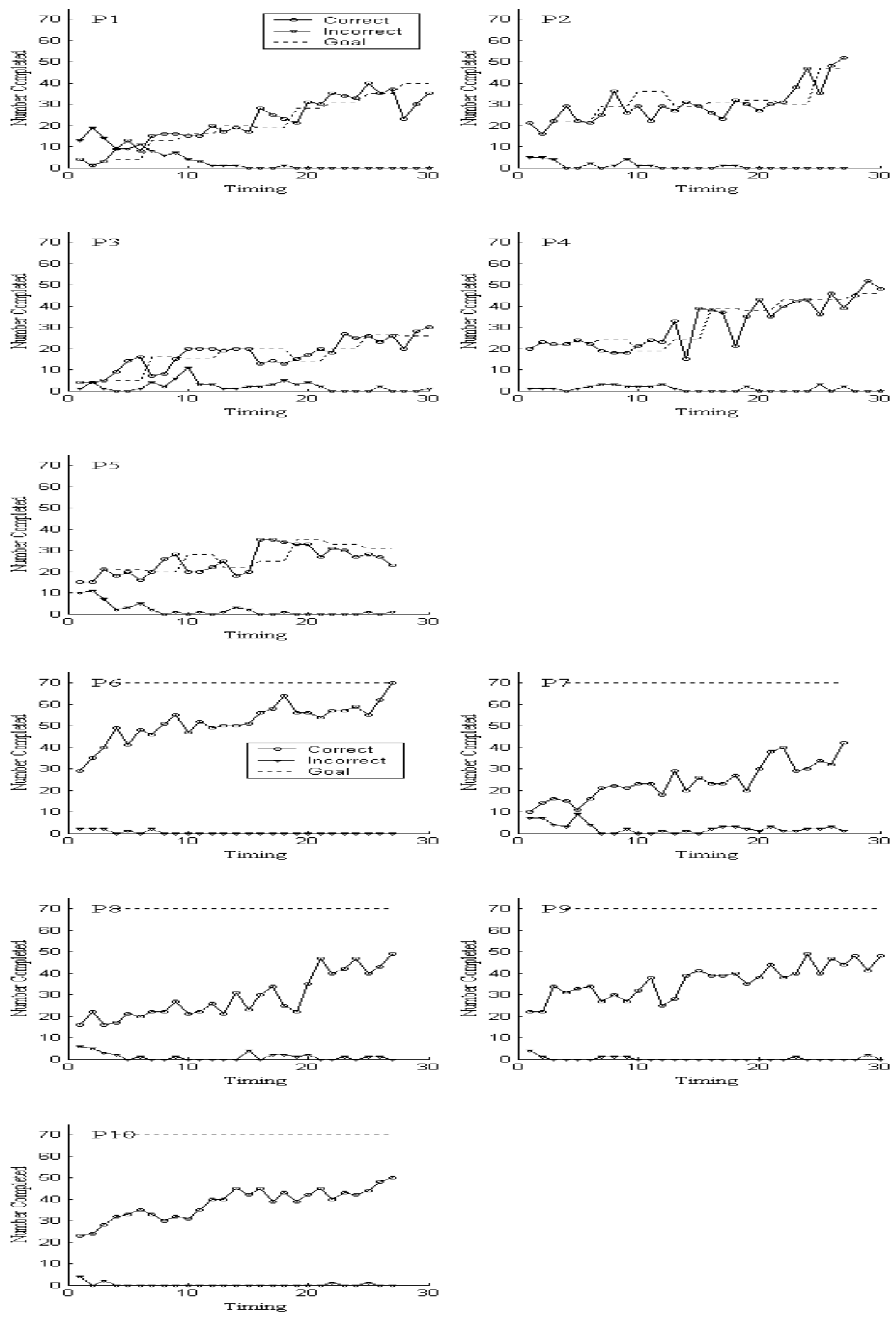

Figure 2. Number of correct back crosses (circles) and incorrect back crosses (triangles) completed by individual skaters in Group 1 (P1-P5) and Group 2 (P6-P10). The goal they were aiming for in each timing from the fourth timing onwards is represented by a broken line. 
Table 2. The slopes and intercepts from lines fitted to Figure 2 using the method of least squares regression.

\begin{tabular}{c|crr} 
Skater & Group & slope & intercept \\
\hline P1 & 1 & 1.133 & 4.035 \\
P2 & 1 & 0.822 & 18.274 \\
P3 & 1 & 0.681 & 6.648 \\
P4 & 1 & 1.058 & 15.030 \\
P5 & 1 & 0.530 & 17.328 \\
\hline P6 & 2 & 0.934 & 38.664 \\
P7 & 2 & 0.927 & 11.202 \\
P8 & 2 & 1.150 & 12.823 \\
P9 & 2 & 0.723 & 25.223 \\
P10 & 2 & 0.799 & 26.709 \\
\hline
\end{tabular}

ing the mean percentage agreement between them. The same formula as that used in Study 1 was used to do this. Overall interobserver reliability is high for correct observations $(\mathrm{M}=93.42 \%$, ranging from $78.72 \%$ to $100 \%$ ). Again percentage agreement for incorrect observations is not calculated as low numbers of incorrects occurred $(M=4.65)$.

\section{DISCUSSION}

This study examined the effects of two different types of performance aims, a hard goal and an easy goal, on skater's rate of performance of a roller skating skill. Overall, differences in performance aims did not accelerate the performance of one group over the other, although improvements were seen in both groups over sessions, confirming again that the method built rate.

The similarity in results between the two goal-setting groups is unusual given that previous goal-setting research has found that hard goals led to better performance than easy or no goals (Earley \& Lituchy, 1991; Latham \& Baldes, 1975; Lee, Sheldon, \& Turban, 2003; Locke, 1968; Locke \& Bryan, 1966; Locke \& Latham, 1990; Seijts, 2001; Smith \& Lee, 1992; Strang, Lawrence, \& Fowler, 1978; Vancouver, Thompson, $\&$ Williams, 2001). While many of these studies did not separate out goal difficul- ty from other experimental variables, Earley and Lituchy (1991) completed two studies which did. Their first study involved students performing maths problems and the second involved working on complex game situations. Both of these tasks were completed under conditions of easy or challenging goals. The easy goal was set at 2SD below the mean performance level of participants who had completed a pilot study, while the hard goal was set 2SD above this mean. It is likely that the easy goal in the current study, of trying to equal or better your previous session's best, is comparably harder than the easy goal for some subjects. Earley and Lituchy found, in contrast to the present study, that participants given challenging goals completed more problems.

Strang, Lawrence and Fowler (1978) also separated out goal difficulty from other variables, in a study giving university students mathematical equations to solve. In two of their experimental conditions, participants had to solve equations accurately within a set period of time and were told after each trial if they had achieved this. Those in an easy-goal condition had to perform more quickly than their slowest time recorded during baseline. Participants in the hard-goal condition had to perform better than their mean performance time recorded 
during baseline. This hard goal appears to be easier than the goal set in the easygoal condition in the current study, where participants were asked to equal or better their previous session's highest score. Those in the hard-goal group of Strang, Lawrence and Fowler's study did solve equations faster, unlike the present findings where no difference was found between goal groups. Taking both of the above studies into account, a fuller assessment of how difficult both the easy and hard goals were in the current study is worth pursuing.

Earley and Lituchy (1991) found that across their two studies $87 \%$ and $89 \%$ of the participants respectively achieved at least the easy goal but only $6 \%$ and $12 \%$ respectively of the participants achieved the difficult goal. It is hard to do a direct comparison for goal difficulty but the current results showed that, in the last session, 3 of the 5 participants $(60 \%)$ in Group 1 achieved the easy goal and 1 of the $5(20 \%)$ of the participants in Group 2 achieved the hard goal. Those data suggest that, in the current study, the hard goal was more difficult than the easy goal. However, even though in this regard there were clear differences between levels of goal difficulty, it is also possible that the easy goal was still not easy enough as only $60 \%$ achieved it. It has been reported by Boyce (1990) and Weinberg, Bruya, Jackson and Garland (1986) that moderate goals are as effective as hard goals. If the 'easy' goal in the current study was moderately different rather than 'easy', the findings of this study would support their statements that moderate goals are as effective as hard goals. Therefore a future study could address this by having a "do your best" condition as is frequently described in the literature.

Other factors aside from goal difficulty may have impacted on the easy goal group to improve their performance rates. One factor studied previously in the literature is that of feedback. Locke and Latham (1990) have reported that goals appear to be more effective when there is feedback, or "Knowledge of Results" and that hard goals with no feedback do not result in better performance than other goals. In the current study both groups were given feedback following each timed minute. However, Group 1, the easy-goal group, was also told at the beginning of each session what their best score had been in the previous session. This additional feedback may have provided a confound if it influenced skaters in this group to work harder in each session over and above the effects of goal difficulty.

Getz and Rainey (2001) and Latham and Seijts (1999) have shown flexible short term goals are more effective than rigid long term goals. It was not the intention of this study to set a short term goal for one group and a long term goal for the other. However, as the hard-goal group was given the same goal each session, and had been told there would be ten sessions, it is possible this goal was a long term one, i.e., that needed to be completed by the end of the study. In contrast, the easy-goal group was given a new goal each session. Such goals meet the criteria of short-term flexible goals described by Getz and Rainey (2001). However, this would predict that participants in the easy-goal group should have performed better than those in the hard-goal group and this did not occur. Thus, this analysis does not account for the present data.

Earley, Connolly and Ekgren (1989) found that easy goals were more effective than hard goals but argued that task complexity influenced the participants' behaviour. Latham and Seijts (1999) agree that as the complexity of a task increases, the magnitude of goal effects decreases. In the current study the task was a simple one which participants were asked to complete in the same manner repeatedly for a minute each time. Therefore this simple task did not 
change in complexity and hard goals should have led to better performance.

That the hard goal here was so difficult to achieve is worth further discussion. For 4 out of 5 skaters in Group 2, the distance between their performance and the actual goal of 70 was still large at the completion of the ten sessions. This distance between actual performance and the set goal has been termed goal-performance discrepancy (Donovan \& Williams, 2003) or goal-discrepancy feedback (Vance \& Colella, 1990). It is postulated that individuals often set lower personal goals when this discrepancy is large (Locke \& Latham, 1990). As already stated, skaters in Group 2 were not asked if they set other goals and there is no other way of finding out if they did. Certainly if they did set lower goals, closer to the easier one set for Group 1, this could account for the similar results in both groups. Consideration should be given for any future studies, to ensuring that the goal set is not so high that there is likely to be a large discrepancy between the goal and actual performance.

Other reports in the literature state that individuals may set personal goals regardless of what goal is assigned to them (Locke, 1991). Even though different types of goals were given to each group, it is not certain that individuals within both groups were not setting alternative goals. For example, it was suggested that individuals in Group 2, with an assigned goal of 70, may have set easy personal goals for each session. However Group 1, which was asked to improve on their last session's highest score, may also have had individuals who set themselves a harder goal than this, more in line with the goal of Group 2 as has occurred in previous studies (Hall, Weinberg, \& Jackson, 1987). It is not clear if skaters set their own additional goals, as they were not asked whether they did so. Therefore this should be considered in further research.
In summary, improvements overall were seen from the first to the last session when fluency building methods were used with roller skaters. However, as both experimental groups showed similar improvement in performance, it is not possible to ascertain from these results whether the use of performance aims aided this improvement. Therefore another study, addressing some of the methodological concerns expressed regarding goal difficulty in this study, was needed to confirm the effectiveness of performance aims alone in precision teaching.

\section{STUDY 3}

As suggested earlier, Latham and Locke (1979) state individuals do not do their best when told to. In the majority of studies reviewed, a specific challenging goal led to better performance than when participants were asked to "do your best". Furthermore, as stated earlier, performance feedback must be given with goals for them to be effective, i.e., if no feedback is given then goals do not result in better performance than when no goals are used (Locke \& Latham, 1990). Latham and Baldes (1975) collected data on the net weight of $36 \mathrm{log}$ ging trucks over a period of 12 months, including an initial 3 months in which logging truck loaders were simply told to "do their best". Logging workers were then assigned the goal of loading trucks up to an average of $94 \%$ of the truck's maximum weight limit. They found that introducing this hard goal after the "do your best" condition immediately led to improved performance on the task. This improvement was then maintained over the period of the study. Other studies have also compared the effect of goals with a 'do your best' condition (Boyce, 1990; Earley et al., 1989; Locke, 1968; Smith \& Lee, 1992; Weinberg, Bruya, Longino, \& Jackson, 1988). In most cases the goals led to better performance levels. Given this, it 
seems sensible to compare the effects of a goal condition with a 'do your best' condition to determine more clearly whether the addition of performance aims leads to improved performance over and above that seen when performance aims are not used.

Taking this into consideration, the first aim of this next study was to confirm that goals, or performance aims, do enhance performance when using fluency building methods. To achieve this, a "do your best" condition was completed, with no feedback provided on rate of performance. It was expected that there would be some improvement during this condition as practice alone is thought to result in improvement (Kuhn \& Stahl, 2003; Mayfield \& Chase, 2002). Therefore this first condition was in effect until performance rates were stable for three sessions, i.e., performance rates were no longer increasing, before a performance aim was then introduced in a second condition. Although precision teachers typically set a performance aim at the rate that a person fluent in that skill could perform, care was taken to ensure that the goal chosen here was hard, yet achievable within the time frame of the study to avoid the confounding effects of goal-performance discrepancy. It was expected that if performance aims were effective, participants would increase their rate of performance following the introduction of the challenging goal. One skill was used for these two conditions.

A second skill was also included. Participants were always told simply to 'do their best' with this skill with the exception of one case which is outlined later. The aim was to monitor the effects of introducing the goal for the first skill on this second skill. In Study 1, two skills were used to see if charting improved performance rates over and above that seen when charting was not used. However, since there were no baseline sessions with both skills uncharted, as charting was introduced from Session 1, it was not possible to conclude that charting one skill had not affected the other skill. In this present study, the baseline condition where there were no set goals for either skill was used to overcome this. The aim was to look for any confounds. It was expected that the addition of the goal for a skill would give increased performance rates for that skill only and that the performance rate of the alternative skill would not change.

\section{Method}

\section{Participants}

Eight children (P1-P8) participated who were attending the local beginner classes. None had participated in the previous study. The participants were 7 girls and 1 boy ranging in age from 4 to 10 years, the average age being 7.4 . The same procedures were used to inform parents and gain consent as in Study 1 .

\section{Apparatus}

A stopwatch was used to time each 1min interval.

\section{Procedure}

The same two skills, forward crossovers and back scissors, as used in Study 1, were used for this study. A similar procedure to Study 1 was also used, except that the participants did not count or use charts. In Condition 1, the researcher plotted data onto linear graphs after each session but ensured that participants did not see these. When a minimum of six sessions had been completed, and the performances of both skills for a skater were judged visually stable by the researcher, i.e., no improvement in either skill was visible for at least three sessions, Condition 2 started with a goal introduced for one skill. This goal was to aim for 20 more correct repetitions of the skill (rounded to the nearest 5) than they had been performing previously in each minute to a maximum of 65 forward crosses and 90 back scissors. Four of the participants (P5-P8) did not par- 
ticipate long enough for their behaviour to be judged stable and for the goal to be introduced. Of the four participants whose behaviour was judged stable, three (P1, P2 and P3) had a goal introduced for forward crosses. Because a fourth participant (P4) was close to the maximum rate for forward crosses, as determined by the set goals above, a goal was set for back scissors for this participant. Once goals were introduced, all participants were told at the end of each timed minute how many correct and incorrect repetitions they had done for that skill only. They were also told that they were aiming for a set number of correct repetitions for the targeted skill. One participant, P1, changed skates in condition 2 but remained in the study long enough to start a third condition where a goal was introduced for the second skill. P2 withdrew after Session 12 and P4 withdrew after Session 13.

\section{RESULTS}

Figure 3 shows the number of correct (solid lines) and incorrect (broken lines) back crossfronts completed in a minute for each skater (P1-P8) in Study 3. The $\mathrm{X}$-axis represents 1 -min timings with three of these in each session. Bold vertical lines indicate changes in condition. A broken vertical line for P1 indicates where this skater changes from roller blades to roller skates. A broken horizontal line shows the goal set for forward crosses. A smaller broken horizontal line shows the goal set for back scissors.

With the exception of two skaters (P5 and P6), all skaters improved their rate of performance on both skills from the first session over Condition 1. P5 was the youngest skater and only completed five sessions before she withdrew. During this time she did not show any improvement in rate of either skill although she was performing both of these skills more confidently by Session 5. P6 did not show any improvement over the first six sessions and a goal would have been introduced in Session 7, however, it was at this point that P6 started to show rate improvements for back scissors. She ceased skating after Session 12 before the data could be considered stable. Her forward crosses also showed a slight rate increase in Session 7 but then remained at this level for the rest of her participation in the study. As P7 and P8 showed rate improvements across condition 1, goals were not introduced before P7 ceased skating in Session 10 and P8 ceased skating in Session 11.

P2 showed a marked increase in rate on both skills once a set goal was introduced for forward crosses in Session 8 . However, although her rate of performance was very similar for both skills prior to the change of condition, once the set goal was introduced, she clearly performed forward crosses at a higher rate than backward scissors.

P3 differed from other participants in that, before the set goal was introduced, she herself counted how many repetitions of a skill she did each minute in many instances, although not consistently and not always with both skills. Other participants may have also done this covertly but it was certain with P3 as she sometimes reported at the end of a minute how many she thought she had done and was usually fairly accurate. When a goal was introduced for forward crosses in Session 15, improvement was initially seen only for her back scissors but this difference disappeared across Condition2. Eight sessions later she reached her goal of 35 forward crosses. Her rate of performance on back scissors was lower at that time.

P4 showed greater improvement throughout Condition 1, compared to the other skaters, eventually reaching the maximum rate possible for forward crosses as determined in Study 1 without any set goals being introduced. 

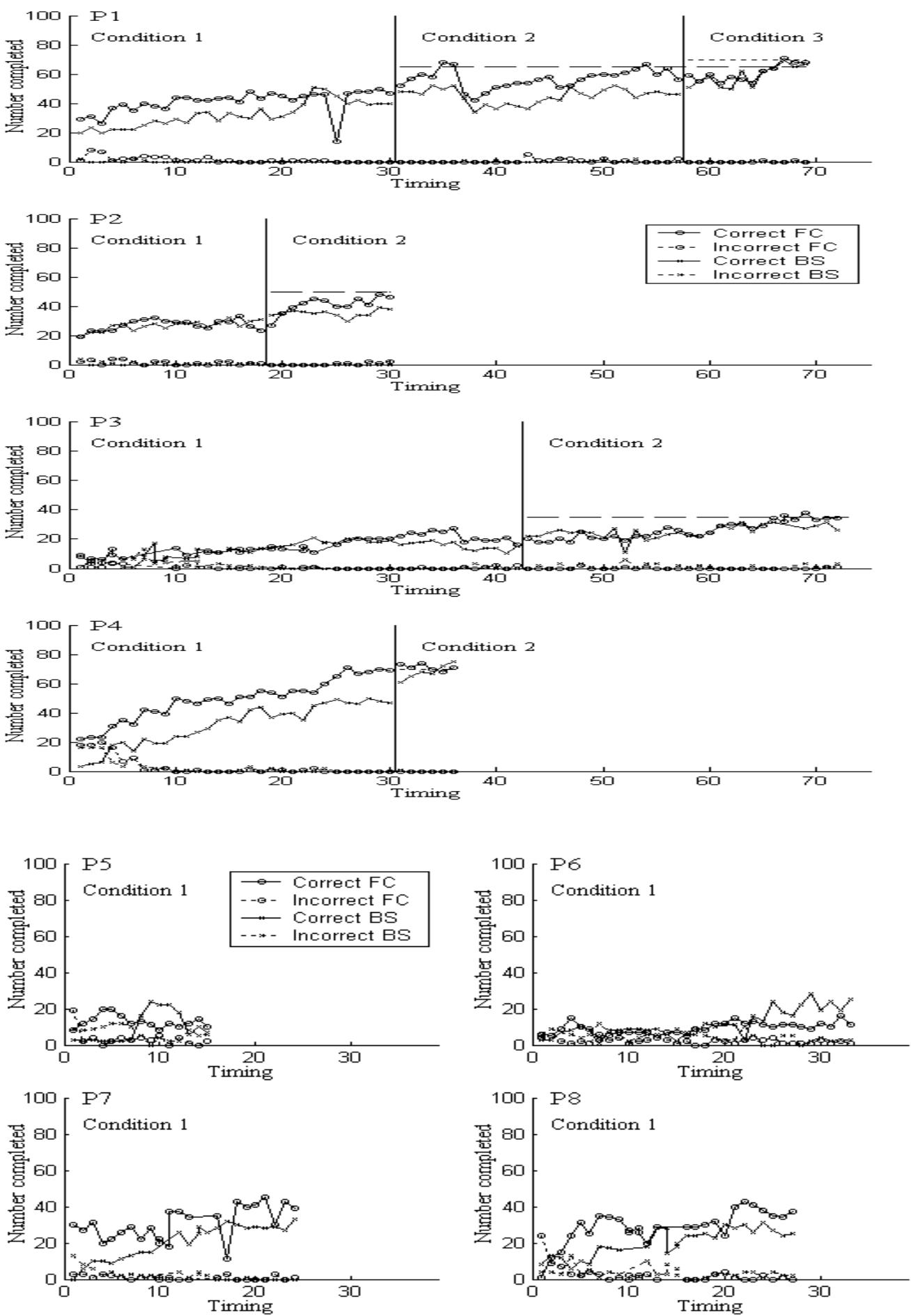

Figure 3. Number of correctly (solid lines) and incorrectly (broken lines) completed forward crosses (circles) and back scissors (crosses) performed in one minute for the participants (P1-P8) in Study 3 across three conditions (no goal, set goal for one skill only, and set goal for both skills). Only one participant (P1) completed three conditions and a further three participants (P2-P4) completed two conditions. Set goals are represented by broken horizontal lines (long dashes for forward cross goals and short dashes for back scissor goals). The remaining participants (P5-P8) did not attend enough sessions to participate in more than the initial condition. 
Although his rate was still improving for back scissors, it was decided that a set goal would be introduced for this skill in Session 12. An immediate rate increase was seen and he surpassed his goal within two sessions.

P1 was the only participant to complete three conditions. Once a goal was set for forward crosses in Session 11, a marked increase in the rate of both skills occurred immediately, with a greater increase being seen for forward crosses. The goal was reached within two sessions of the condition change, in Session 12. P1 changed from roller blades to roller skates in Session 13, and a drop was seen in the rate of both skills as a result. However, both skills continued to improve and she reached the set goal again in session 18. When a goal was introduced for back scissors in Session 20 , an immediate increase in rate was seen for this skill so that the rate of both skills was now similar. P1 did not reach her goal for back scissors before stopping after session 23 .

Lines were fitted to the last 6 timings of Condition 1 and the first 6 timings of Condition 2 using the method of least squares and compared over 4 skaters (P1-P4), to see if there was a significant difference on rate of performance once a goal was introduced for one skill in Condition 2. With alpha set at .05, a significant difference was found for the targeted skill, $\mathrm{t}(3)=4.185(\mathrm{M}=2.450$, $\mathrm{SD}=1.195)$, but not found for the untargeted skill, $\mathrm{t}(3)=.250(\mathrm{M}=.157, \mathrm{SD}$ $=1.254$ ).

\section{DISCUSSION}

Study 3 examined the effects of goals, or performance aims, on skater's rate of performance for two roller skating skills. Initially, all skaters showed improvement over a baseline phase where no goals had been introduced. Following the introduction of a goal, there were accelerated performance rates for the targeted skill, and also some smaller im- provements for the untargeted skill. Therefore goals did appear to increase the rates of performance of both skills over and above those seen when no goals were used.

Latham and Baldes (1975) found that when a hard goal was given to logging truck drivers, following a baseline condition where they were asked to "do their best", their performance improved immediately, a result similar to that here. In the sporting area, Anderson, Crowell, Doman, and Heward (1988) who, after a baseline condition, introduced feedback then goals with icehockey skaters found that legal body checking rates (hit rate) increased immediately, a finding similar to that in the current study. Thus the general results of this study add further support to the large body of literature regarding the effect of goals.

The main procedural change resulting from the introduction of a goal here was the amount and type of feedback being given. The introduction of a goal meant that the skater was given the number of correct and incorrect repetitions of the targeted skill completed in the timed minute. Often, after this, they drew comparisons between their current performance of that skill and the goal. This comparison and feedback occurred only for the targeted skill. However, the results generally showed that the introduction of a goal impacted on both skills. While this impact was not as large on the untargeted skill for 2 skaters, it was greater for that skill for 1 skater (P3). It did not impact on the untargeted skill for the last skater possibly because he was already performing this skill as at high a rate as he was able. Contrary to the present results, Ward and Carnes (2002) previously found that the introduction of goal-setting with one skill did not affect other skills being monitored. One difference between the two studies, which may have led to the differing of results, is in the nature of the goals used. The 
participants in Ward and Carnes' study were focused on performing accurately each time they were given an opportunity to perform the targeted skill. In contrast, the participants here were focused not only on performing the skill accurately, but also on performing the skill faster. It is possible that the resulting speed with which participants in this study performed one skill may have carried over to the untargeted skill, even in the absence of definitive feedback showing how much faster they were performing it.

Unfortunately the withdrawal of four participants before a goal could be introduced resulted in a reduction of possible comparisons between baseline and goal-setting, leaving only 4 participants where the effects of goal setting could be evaluated. However, it is possible to make some comparisons between the results in Condition 1 here and the results from Study 1 as all skaters were selected in a similar way and the same two skills were used in both studies. Study 1 participants completed at least eight sessions, as did six of the eight skaters in the current study (P1, P3, P4, $\mathrm{P} 6, \mathrm{P} 7$ and $\mathrm{P} 8)$, during the baseline condition where no goals or feedback were given. So, excluding P2 and P5 from the current study leaves one group of six skaters where goals had not been introduced. There are two groups of six skaters from Study 1, where goal-setting was used, that could be used for comparison. Although no difference was found in Study 1, it was decided to keep the two groups separate and compare them with the baseline group here. This comparison of eight session's data for each skater in these three groups meant that the effect of goal-setting, over and above progress resulting from timed minute practices, could be evaluated.

Slopes were fitted to the data for both forward crosses and back scissors for each participant for the first eight session's data using least squares regres- sion. One-way ANOVAs showed that, with alpha set at .05 , there was no significant difference in slope between the three groups for forward crosses, $\mathrm{F}(2$, $15)=1.744$, (partial $\eta^{2}=.189$ and observed power .308), or for back scissors, $\mathrm{F}(2,15)=.772$, (partial $\eta^{2}=.093$ and observed power .157).

The first and last timings were also compared between groups using a repeated measures ANOVA. With alpha set at .05 , the interaction of group and timings was not statistically significant for forward crosses, $F(2,15)=1.556$, (partial $\eta^{2}=.172$, observed power $=$ $.278)$ or back scissors, $F(2,15)=.247$, (partial $\eta^{2}=.032$, observed power $=$ .082). There were also no significant differences between groups for forward crosses, $F(2,15)=.831$, (partial $\eta^{2}$ $=.100$, observed power $=.166$ ), or for back scissors, $\mathrm{F}(1,10)=1.949$, (partial $\eta^{2}=.206$, observed power $=.340$ ). However, a significant difference was found between first and last timings for both forward crosses, $\mathrm{F}(1,15)=81.299$, (partial $\left.\eta^{2}=.844\right)$ and back scissors, $\mathrm{F}(1,15)$ $=65.280$, (partial $\eta^{2}=.813$ ). These results show then that the 'do your best' group in the current study performed as well as the goal-setting groups used in Study 1.

One reason that skaters may have progressed so well in the absence of goals is that other components of the rate building method were effective. Precision teaching uses short, timed practice periods. This would fit within the definition of deliberate practice (Ericsson \& Charness, 1994). Ericsson and Charness argue that deliberate practice allows individuals to perform at the same level as experts. In essence, this is what precision teaching is aiming to achieve as it encourages students to perform at the same level as a person fluent in that skill. Therefore, it is argued that deliberate practice may be responsible for the increase in performance rates seen in the absence of performance aims. 
While no difference was found for the three groups over the first eight sessions, when goals were introduced after behaviour was stable in the 'do your best' condition in the current study, goalsetting led immediately to increases in performance rates for 3 of the 4 skaters. Accuracy was fairly high at this stage, as seen by low numbers of errors in Figures 3 , and so these changes in performance rate reflect an increase in fluency alone. More interesting, a goal was introduced for P4 even though his performance had continuously increased in the absence of set goals and had not yet stabilized and an immediate increase was seen in his performance rate for this skill. This demonstrates that, even though the fluency building method in general was resulting in increased performance rates similar to those seen in Study 1, introducing a goal resulted in even greater increases. It is not clear however, why goals should be more effective following a period of 'do your best', as seen here, while not resulting in greater changes earlier, as in Study 1. There are no obvious differences between groups of subjects that would mask such a difference.

Participants in the previous study were asked to attend only ten sessions and all completed at least eight. In contrast, the current study involved stability and required a large number of sessions. Over the course of the study all but two of the eight participants withdrew with four of the participants withdrawing prior to a goal being set. It is possible that the number of sessions required alone or the absence of feedback might have contributed to this loss. During baseline the intervening training given when there were many errors provided some feedback on performance, this feedback reduced as the skill was mastered and errors decreased. As a result, later sessions involved practicing the same two skills over and over again with little feedback. All skaters in this study became less willing to participate as the number of sessions grew and feedback decreased. It may be that keeping sessions to a lower number, and providing consistent feedback separate from the performance aim, may help keep participants in the study which would overcome this problem in future.

In summary, the results of this study are consistent with other studies that have found goal-setting to be effective, as the introduction of goals did increase performance rates following a period of 'do your best'. However, it was also observed that considerable increases in performance rates were seen in the absence of goals. It is argued that this may have occurred because of the effects of 'deliberate practice'. Further research is needed to explore this. Results also showed that the setting of goals with one skill impacted positively on a second skill that had no set goals and it is possible that this was due to the goal placing an emphasis on rate of performance.

\section{GENERAL DISCUSSION}

One of the aims of this research was to see if precision teaching could be applied to a sport such as rollerskating. Previously much of the literature around precision teaching has focused on academic skills (Chiesa \& Robertson, 2000; Kessissoglou \& Farrell, 1995; Lindsley, 1992a, 1992b). The results from all three studies presented here have shown that the use of precision teaching, with and without charting, resulted in skaters performing skating skills faster. Furthermore, it appears that, similar to the findings of Johnson (1997) and Spence and Hively (1993) for academic skills, skater's performances became more fluent than they would have been without precision teaching.

The second aim of this research was to examine some components of precision teaching to consider their contribution to the overall effectiveness of the rate building procedure. The first component 
studied here was the use of celeration charts, an integral part of precision teaching (Raybould \& Solity, 1982; West et al., 1990; White, 1986). While charts are reported to serve several different functions (Lindsley, 1971), findings from this research were that charts did not accelerate performance over and above that observed in the absence of charting. It was possible that, due to the methodology used in Study 1, the effects of charting one skill may have carried over to a second uncharted skill, as occurred in Study 3. However, the comparison of data for Study 1 and Study 3 showed no differences and it can be argued that charting was not effective in accelerating performance rates over and above that seen when charting was not used. Therefore, it is suggested here that charting is not necessary for increasing performance rates, at least with these skating skills.

The second component studied here was the use of performance aims, or goals. As explained earlier, there has not been any previous precision teaching research done on the effect of performance aims, although it is stated that high performance aims maximize learning (Koorland et al., 1990; Lindsley, 1992b), therefore the current research was based on the vast literature in the area of goal-setting. While there are a large amount of studies supporting the use of goal-setting (Locke \& Latham, 1990), mixed results were found here. As only one condition in one of the three studies did not include goal-setting, and the performances of skaters in this condition were compared with those in another study altogether, other factors may have impacted on the results. Thus, it would be a natural progression from here to compare skaters within one study, which included a no-goal condition, to see if the same results were found.

No difference was found between moderate and hard goals. In the goal set- ting literature hard goals are said to direct attention toward goal-related activities, lead to greater effort, and encourage individuals to work faster and more intensely for a short period of time (Locke \& Latham, 2002). It is argued that precision teaching also directs attention and so it is possible that no difference was found between moderate and hard goals because when these goals are combined with precision teaching, attention is directed to performance. Interestingly, no difference was found between goal setting and practice only when comparing Study 3 baseline results with findings in Study 1. Again, the precision teaching may have contributed to performance increases in the absence of goals because of directed attention.

In summary, there has been a large body of evidence collected demonstrating that precision teaching as a method works in improving performance rates, yet there has been limited research into why it is effective. The current investigation has been a step towards doing this. Two components, charting and performance aims, were targeted here. Overall, it appears that charting does not accelerate performance over and above what is seen when charting is not used while performance aims do appear to have some effect, but only when introduced after a period of time where no goal has been set. More generally, the results have also shown that precision teaching, although typically used in educational fields, can also be applied to the sport of roller skating.

\section{REFERENCE}

Alper, T. G., \& White, O. R. (1971). Precision Teaching: A tool for the school psychologist and teacher. Journal of School Psychology, 9(4), 445-454.

Anderson, D. C., Crowell, C. R., Doman, M., \& Howard, G. S. (1988). Performance posting, goal setting, and activity-contingent praise as applied to a university hockey team. Journal of Applied Psychology February, 73(1), 87-95. 
Ayers, S. K., Potter, R. E., \& McDearmon, J. R. (1975). Using reinforcement therapy and precision teaching techniques with adult aphasiacs. Journal of behavior therapy and experimental psychiatry, 6(4), 301-305.

Binder, C., \& Watkins, C. L. (1990). Precision Teaching and Direct Instruction: Measurably superior instructional technology in schools. Performance Improvement Quarterly, 3(4), 74-96.

Boyce, B. A. (1990). Effects of goal specificity and goal difficulty upon skill acquisition of a selected shooting task. Perceptual and Motor Skills, 70, 1031-1039.

Boyce, B. A., Johnston, T., Wayda, V. K., Bunker, L. K., \& Eliot, J. (2001). The effects of three types of goal setting conditions on tennis performance: A field-based study., Journal of Teaching in Physical Education (Vol. 20, pp. 188): Human Kinetics Publishers, Inc.

Brandstetter, G., \& Merz, C. (1978). Charting scores in precision teaching for skill acquisition. Exceptional children, 45(1), 42-48.

Brett, J. F., \& VandeWalle, D. (1999). Goal orientation and goal content as predictors of performance in a training program. Journal of Applied Psychology, 84(6), 863.

Chiesa, M., \& Robertson, A. (2000). Precision Teaching and fluency training: making maths easier for pupils and teachers. Educational Psychology in Practice, 16(3).

Donovan, J. J., \& Williams, K. J. (2003). Missing the mark: Effects of time and causal attributions on goal revision in response to goal-performance discrepancies. Journal of Applied Psychology, 88(3), 379.

Earley, P. C., Connolly, T., \& Ekgren, G. (1989). Goals, strategy development, and task performance: Some limits on the efficacy of goal setting. Journal of Applied Psychology, 74(1), 24.

Earley, P. C., \& Lituchy, T. R. (1991). Delineating goal and efficacy effects: A test of three models. Journal of Applied Psychology, 76(1), 81 .

Ericsson, K. A., \& Charness, N. (1994). Expert performance: Its structure and acquisition. American Psychologist August, 49(8), 725747.

Fairall, D. G., \& Rodgers, W. M. (1997). The effects of goal-setting method on goal attributes in athletes: A field experiment. Journal of Sport and Exercise Psychology, 19(1), 1-16.

Getz, G. E., \& Rainey, D. W. (2001). Flexible short-term goals and basketball shooting performance. Journal of Sport Behavior, 24(1), 31 .
Gilliland, S. W., \& Landis, R. S. (1992). Quality and quantity goals in a complex decision task: Strategies and outcomes. Journal of Applied Psychology, 77(5), 672.

Hall, H. K., Weinberg, R. S., \& Jackson, A. (1987). Effects of goal specificity, goal difficulty, and information feedback on endurance performance. Journal of Sport Psychology, 9, 43-54.

Hatzigeorgiadis, A., \& Biddle, S. (1999). The effects of goal orientation and perceived competence on cognitive interference during tennis... Journal of Sport Behavior, 22(4), 479.

Johnson, E. C. (1971). Precision teaching helps children learn. Teaching exceptional children, 3, 106-110.

Johnson, K. R. (1997). Morningside Academy. Behavior and Social Issues, 7(1), 31-35.

Johnson, K. R., \& Layng, T. V. (1996). On terms. The Behavior Analyst, 19(2), 281288.

Johnson, K. R., \& Layng, T. V. J. (1992). Breaking the structuralist barrier: Literacy and numeracy with fluency. American Psychologist November, 47(11), 1475-1490.

Joyce, B. (1988). Precision Teaching: A manual for classroom teachers.

Joyce, B., \& Moxley, R. A. (1988). August Dvorak (1894-1975): Early expressions of applied behavior analysis and precision teaching. The Behavior Analyst, 11(1(Spring)), 33-40.

Kanfer, R., \& Ackerman, P. L. (1994). Goal setting, conditions of practice and task performance: A resource allocation perspective. Journal of Applied Psychology, 79(6), 826.

Kessissoglou, S., \& Farrell, P. (1995). Whatever happened to Precision Teaching? British Journal of Special Education, 22(2), 60-63.

Koorland, M. A., Keel, M. C., \& Ueberhorst, P. (1990). Setting aims for precision learning. Teaching Exceptional Children, 22(3), 6466.

Kozlowski, S. W. J., Gully, S. M., Brown, K. G., Salas, E. S., M., E., \& Nason, E. R. (2001). Effects of training goals and goal orientation traits on multidimensional training outcomes and... Organizational Behavior \& Human Decision Processes, 85(1), 1.

Kuhn, M., R, \& Stahl, S. A. (2003). Fluency: A review of developmental and remedial practices. Journal of Educational Psychology, 95(1), 3-21.

Latham, G. P., \& Baldes, J. J. (1975). The "Practical Significance" of Locke's theory of goal setting. Journal of Applied Psychology, 60(1), 122. 
Latham, G. P., \& Kinne, S. B. (1974). Improving job performance through training in goal setting. Journal of Applied Psychology, 59(2), 187.

Latham, G. P., \& Locke, E. A. (1979). Goal setting-A motivational technique that works. Organizational Dynamics, 8(2), 68.

Latham, G. P., \& Seijts, G. H. (1999). The effects of proximal and distal goals on performance on a moderately complex task. Journal of Organizational Behavior, 20(4), 421.

Lee, F. K., Sheldon, K. M., \& Turban, D. B. (2003). Personality and the goal-striving process: The influence of achievement goal patterns, goal level, and mental focus on performance and enjoyment. Journal of Applied Psychology, 88(2), 256.

Lindsley, O. R. (1990). Precision teaching: by teachers for children. Teaching Exceptional Children, 22(3), 10-15.

Lindsley, O. R. (1971). Precision teaching in perspective: an interview with Ogden Lindsley. Teaching Exceptional Children, 3(2), 114-119.

Lindsley, O. R. (1992a). Why aren't effective teaching tools widely adopted? Journal of Applied Behavior Analysis, 25(Spring), 2126.

Lindsley, O. R. (1992b). Precision teaching: discoveries and effects. Journal of Applied Behavior Analysis, 25(1), 51-57.

Locke, E. A. (1968). Effects of knowledge of results, feedback in relation to standards, and goals on reaction-time performance. The American Journal of Psychology, 81(4), 566-576.

Locke, E. A. (1991). Problems with goal-setting research in sports - and their solution. Journal of Sport and Exercise Psychology, 13, 311-316.

Locke, E. A. (1993). Facts and fallacies about goal theory. Psychological Science, 4(1), 63.

Locke, E. A., \& Bryan, J. F. (1966). The effects of goal setting, rule learning, and knowledge of score on performance. American Journal of Psychology, 79, 451-457.

Locke, E. A., \& Latham, G. P. (1985). The application of goal setting to sports. Journal of Sport Psychology, 7, 205-222.

Locke, E. A., \& Latham, G. P. (1990). A theory of goal setting and task performance. Englewood Cliffs: Prentice Hall.

Locke, E. A., \& Latham, G. P. (2002). Building a practically useful theory of goal setting and task motivation. American Psychologist, 57(9), 705.

Mayfield, K., \& Chase, P. (2002). The effects of cumulative practice on mathematics prob- lem solving. Journal of Applied Behavior Analysis, 35(2), 105-123.

Meacham, M.-L., \& Wiesen, A.-E. (1969). Changing classroom behavior: A manual for Precision Teaching.

Polson, D. (2003, 22-Oct-2002). Precision teaching module [Web page]. Retrieved 19 September, 2003, from the World Wide Web: http://psych.athabascau.ca/html/387/Open Modules/Lindsley/

Raybould, T., \& Solity, J. (1982). Teaching with precision. Special Education: forward trends, 9(2), 9-13.

Rizzo, T., Woodard, R., Ozmun, J. C., Piletic, C. K., Faison-Hodge, J., \& Sayers, L. K. (2003). A review of goal setting and task performance. Adapted Physical Activity Quarterly, 20(2), 207.

Seijts, G. H. (2001). Setting goals. Ivey Business Journal, 65(3), 40.

Smith, M., \& Lee, C. (1992). Goal setting and performance in a novel coordination task: Mediating mechanisms. Journal of Sport and Exercise Psychology, 14, 169-176.

Spence, I., \& Hively, W. (1993). What makes Chris practice? Educational Technology, 33(10), 15-20.

Strang, H. R., Lawrence, E. C., \& Fowler, P., C. (1978). Effects of assigned goal level and knowledge of results on arithmetic computation: A laboratory. Journal of Applied Psychology, 63(4), 446.

Thill, E. E., \& Cury, F. (2000). Learning to play golf under different conditions: their effects on irrevelant thoughts and on subsequent control strategies. European Journal of Social Psychology, 30, 101-122.

Vance, R. J., \& Colella, A. (1990). Effects of two types of feedback on goal acceptance and personal goals. Journal of Applied Psychology, 75(1), 68.

Vancouver, J. B., Thompson, C. M., \& Williams, A. A. (2001). The changing signs in the relationships among self-efficacy, personal goals, and performance. Journal of Applied Psychology, 86(4), 605-620.

Wanlin, C. M., Hrycaiko, D. W., Martin, G. L., \& Mahon, M. (1997). The effects of a goalsetting package on the performance of speed skaters. Journal of Applied Sport Psychology, 9(2), 212-228.

Ward, P., \& Carnes, M. (2002). Effects of posting self-set goals on collegiate football players' skill execution during practice and games. Journal of Applied Behavior Analysis, 35(1), 1-12.

Weinberg, R. S. (2002). Goal setting in sport and exercise:Research to practice. In J. L. Van Raalte \& W. B. Britton (Eds.), Exploring Sport and Exercise Psychology (pp. 25-48). 
Washington DC: Merican Psychological Association.

Weinberg, R. S., Bruya, L. D., Jackson, A., \& Garland, H. (1986). Goal difficulty and endurance performance: A challenge to goal attainability assumption. Journal of Sport Behavior, 10, 81-91.

Weinberg, R. S., Bruya, L. D., Longino, J., \& Jackson, A. (1988). Effect of goal proximity on endurance performance of primarygrade children. Journal of Sport \& Exercise Psychology, 10, 81-91.

West, R. P., Young, K. R., \& Spooner, F. (1990). Precision Teaching. An Introduction. Teaching Exceptional Children, 22(3), 4-9.

White, O. R. (1986). Precision teaching- precision learning. Exceptional Children, 56(6), 522-534.

White, O. R., \& Haring, N. G. (1980). Exceptional Teaching (Second ed.). Columbus: Charles E. Merril Publishing Co.

Yawkey, T. D., \& O'Meara, K. R. (1974). Precision techniques in the management of children's behavior in an open education classroom. Instructional Psychology, 1(4), 9-17. 